\title{
Si P entonces Q. Lógica, instanciación y norma: Ia importancia de la lógica en el razonamiento legal y la práctica judicial
}

David Modesto Güette Hernández

Universidad del Norte, Colombia 


\title{
Si P entonces Q. Lógica, instanciación y norma: la importancia de la lógica en el razonamiento legal y la práctica judicial ${ }^{\star}$
}

\begin{abstract}
Resumen: las presentes líneas tienen como propósito justificar la importancia de la lógica en el razonamiento legal y en la práctica judicial, entendida esta última, como aquella en la que se desenvuelven abogados y jueces. Se trata de un artículo de reflexión, además es un avance de la investigación titulada: mínimos argumentales de la decisión judicial, y constituye una propuesta analítica, que parte de un problema contemporáneo, referido a la lógica y su utilidad práctica. La propuesta va más allá del mero ejercicio filosófico y se dirige a abogados litigantes para mostrarles cómo la lógica incide en la elaboración de formas procesales como la demanda.
\end{abstract}

Palabras clave: lógica, instanciación, norma, razonamiento jurídico, práctica jurídica, textura abierta del lenguaje.

\section{P then Q. Logic, instantiation and norm: the importance of logic in the legal reasoning, and the judicial practice}

\begin{abstract}
: the purpose of these lines is to justify the importance of logic within of legal reasoning and judicial practice, understood as the one in which lawyers and judges operate. It is a reflection article, it is also an advance of the investigation entitled: minimum arguments of the judicial decision, and constitutes an analytical proposal, which starts from a contemporary problem, referring to logic and its practical utility. The proposal goes beyond the mere philosophical exercise and is aimed at litigating lawyers to show them how logic affects the elaboration of procedural forms such as demand.
\end{abstract}

Keywords: logic, instantiation, norm, legal reasoning, legal practice, open texture of language.

Fecha de recepción: 18 de noviembre de 2018

Fecha de aceptación: 10 de abril de 2019

Forma de citar (APA): Güette-Hernández, D. (2019). Si P entonces Q. Lógica, instanciación y norma: la importancia de la lógica en el razonamiento legal y la práctica judicial. Revista Filosofía UIS, 18(2), doi: 10.18273/revfil.v18n2-2019011

Forma de citar (Harvard): Güette-Hernández, D. (2019). Si P entonces Q. Lógica, instanciación y norma: la importancia de la lógica en el razonamiento legal y la práctica judicial. Revista Filosofía UIS, 18(2), 207-233.

David Modesto Güette Hernández: colombiano. Magíster en Derecho. Doctorando en Derecho en la Universidad del Norte y profesor en la Universidad del Magdalena, Colombia.

Correo electrónico: dmguette@uninorte.edu.co

ORCID: 0000-0001-7012-3231

*Artículo de reflexión derivado de investigación. 


\section{Si P entonces Q. Lógica, instanciación y norma: la importancia de la lógica en el razonamiento legal y la práctica judicial'}

\section{Introducción}

Con el ascenso de la teoría de la argumentación jurídica (TAJ) como herramienta racionalizadora del contenido de la decisión judicial y el razonamiento legal, se ha generalizado de manera inadecuada entre estudiantes de derecho, e incluso entre quienes participan en la práctica jurídica (abogados litigantes, jueces y magistrados), que la lógica no cumple ningún papel. En las presentes líneas se pretende mostrar que se trata de una afirmación relativa y extrema, pues, si bien, es dable afirmar que el llamado paleo-positivismo al que se refiere Ferrajoli ${ }^{2}$, constituye una práctica obsoleta, que debe dejarse de lado, no se puede con ello asumir que la lógica se torne en innecesaria e inútil.

Un primer argumento de autoridad al que puede apelarse para justificar la importancia de la lógica en el razonamiento legal, lo encontramos en MacCormick (2016) en especial cuando nos muestra la relación entre la lógica y la retórica, en específico en el momento en que la lógica sustenta la retórica, esto es, al identificar los universales con los que debe llevarse a cabo la instanciación, sobre la que la retórica trabajará. En este punto se torna relevante la noción Kelseniana $(2013)^{3}$ de norma como regla derivada o producto interpretativo cuya estructura es condicional e hipotética, que surge además en un escenario en el que las reglas se caracterizan por lo que Hart (1998) denomina textura abierta del lenguaje y que determina el final de la fase jurídica propiamente dicha y el inicio de la fase probatoria, en específico, al identificar los hechos jurídicamente relevantes e iniciar la búsqueda del respaldo probatorio.

\footnotetext{
${ }^{1}$ El presente artículo fue presentado como ponencia en el marco del III Coloquio de Argumentación llevado a cabo en la Universidad EAFIT, los días 15, 16 y 17 agosto de 2018.

${ }^{2}$ El término paleo-positivismo, lo utiliza para diferenciar aquella concepción positivista, que entiende el derecho como aquel que cumple con una forma y, por lo tanto, se realizan respecto de él, solo juicios de validez (Ferrajoli, 2006, pp. 27-28).

${ }^{3}$ Punto en el que además concurren Guastini (2014), Alf Ross (2000), Taruffo (2011), entre muchos otros.
} 
El fundamento normativo esencial que marca la importancia de lo afirmado en precedencia, lo encontramos en el artículo 167 del Código General del Proceso. Allí, se impone a las partes la obligación de acreditar el supuesto de hecho de las normas que consagran el efecto jurídico que ellas persiguen, lo que demuestra que el derecho trabaja con una noción lógica de la norma jurídica que se estructura bajo la forma: si $p$ entonces debe ser $q$, lo que supone a la vez, y en aras de poder ejercitar de manera adecuada su despliegue probatorio, identificar los supuestos de hecho de la norma, pues solo ante la acreditación de estos, puede ordenarse la aplicación de las consecuencias jurídicas contenidas en ella (la norma). González Lagier (2011) apadrina la misma idea, y lo hace a partir del modelo lógico-pragmático de Toulmin (2003), quien, a su vez, toma en cuenta la estructura de los argumentos que trabaja Copi y Cohen (2010), y que Bonorino (2011) implementó en la escuela de formación judicial Rodrigo Lara Bonilla. Todo lo anterior sin dejar de lado las fases lógica y pre-lógicas que identifica Viehweg (2007) y los niveles de la decisión judicial con que trabaja MacCormick (1978).

\section{La lógica y el razonamiento jurídico}

Hablar de la importancia de la lógica dentro del razonamiento jurídico puede generar escepticismo pues hay una consideración generalizada en abogados litigantes, jueces y magistrados, producto de la prioridad en la educación filosófica del derecho, sobre corrientes llamadas por algunos como postpositivistas o iusnaturalistas ${ }^{4}$ que han querido mostrar al positivismo como una forma ortodoxa e insuficiente para la aplicación y entendimiento del derecho, ideas que se han desarrollado en programas de educación en derecho a nivel de pregrado y posgrados y al interior de la escuela de formación judicial.

Dos anécdotas me llegan a la mente cuando repaso mi proceso de formación judicial. La primera en mis estudios de maestría, en la que se me inculcó que tanto Kelsen (2013) como Hart (1998) podían connotarse como positivistas normativistas, tesis muy cercana a lo que denomina Ferrajoli (2006) como paleo-positivista, tomando como fundamento para esa clasificación, la lectura que se realizaba a Dworkin (2005) (2014), y justificándolo a partir de un argumento a contrario sensu, de manera que, si este último criticaba el positivismo, entonces él era iusnaturalista. Esta misma lectura del positivismo a partir de las obras de Dworkin (2005) (2014) fueron desarrolladas por la escuela de formación judicial Rodrigo Lara Bonilla (EJRLB), tomando como principal artífice de estas interpretaciones a Bonorino (2006), quien en el libro: Filosofía del derecho, planteaba que el naturalismo se encontraba caracterizado por tres tesis: (1) "existen principios de moralidad eternos y universalmente verdaderos" (Bonorino y Peña Ayazo, 2006, p. 10) ; (2) "el contenido de dichos principios es cognoscible por el hombre empleando las herramientas de la razón humana" (2006, p. 10); (3) "sólo se

${ }^{4}$ Dentro de este grupo se han incluido autores como Alexy (2007) (2012) y Dworkin (2014) (2005). 
puede considerar 'derecho' (leyes positivas) al conjunto de normas dictadas por los hombres que se encuentren en concordancia con lo que establecen dichos principios" (2006, p. 10). Tomando en cuenta esa caracterización, a contrario sensu planteaba que el positivismo era aquella corriente que se oponía a la tesis del naturalismo, siendo derecho para los positivistas aquel conjunto de normas que no se someten a ninguna prueba relacionada con el valor moral de sus contenidos (2006, p. 12).

La proliferación de esta corriente suscitó un auge por formar jueces hércules y rechazar la formación de jueces hartianos. Pero esa no fue la única consecuencia, pues aduciendo que la lógica era el mecanismo connatural para los jueces positivistas, se trató de erradicar esa tendencia, mostrando que la única forma de poder llegar a una única respuesta correcta, propia de los jueces hércules era aplicando el método iusnaturalista, que se definía también a contrario sensu del iuspositivista y, por ende, al ser algo de menos alcurnia, había que abandonar el uso de la lógica y que esta no servía para nada.

La segunda anécdota que enunciaré fue la que me permitió comprender las afirmaciones de la primera anécdota. Esta tuvo suceso en un curso de formación de formadores para el módulo de argumentación jurídica ofrecido por la escuela, en la que el mismo Bonorino fungía como formador. En esta ocasión, el auditorio se encontraba conformado por jueces y magistrados, y más o menos dos litigantes. Al inicio de la intervención el profesor Bonorino planteó una pregunta: ¿saben para qué sirve la lógica?, a la que uno de los miembros del grupo, sin asomo de duda, con una voz alta, y sin necesidad de pedir el uso de la palabra respondió: ipara un carajo! Hubo un asentimiento minoritario que se reflejó en unas pocas sonrisas que se asomaban como murmullos en el auditorio, expresando que era una verdad incuestionable. Para sorpresa de esa minoría, ese auditorio tenía dentro de sus miembros, jueces y magistrados que habían realizado estudios en Europa sobre argumentación judicial y, además, Bonorino pretendía mostrar durante su presentación que la lógica era el fundamento esencial de la argumentación jurídica. La cara de asombro de varios integrantes, entre ellos mi compañero de ubicación, (Juez Administrativo), no pudo ser disimulada cuando el profesor Bonorino, le hizo ver que cometía un gran error y que el curso de formación se orientaría a explicar modos lógicos como base para la construcción de argumentos.

Hoy estoy completamente seguro que esas lecturas de Hart, a partir de Dworkin, nos hicieron mucho daño; que Hart, y Dworkin, se parecen más que lo que se contradicen, coincidiendo en ese punto con García Amado (2015), cuando establece que la discusión esencial entre las dos corrientes no radica en la naturaleza y estructura de las "reglas", pues es de su parecer (igual al mío) que en ambos sistemas y ambas tesis, se reconocen los principios, siendo el punto de 
ruptura que para los iusnaturalistas ${ }^{5}$ existen reglas no positivadas, mientras que para los iuspositivistas todo el derecho es positivo ${ }^{6}$.

Esta tesis, de unidad, fue desarrollada in extenso por MacCormick (2016), mostrando cómo dentro de un sistema concebido como positivista, caracterizado por la textura abierta del lenguaje o el derecho, se requería la lógica como forma de justificación, en los niveles de argumentación que presenta, y cómo es necesario entrelazar tanto reglas como principios para poder dotar de coherencia un sistema.

Tomando en cuenta el anterior planteamiento y luego de haber justificado que la formación iusnaturalista que pretendía tergiversar y soslayar al positivismo como una corriente inaplicable, incompleta e incomprensiva del derecho graba dentro de esas discusiones a la lógica como forma de aplicación connatural, me enfocaré ahora en explicar la importancia de la lógica al interior del razonamiento jurídico.

\section{La importancia de la lógica en el razonamiento jurídico}

Una de las más importantes razones que pueden esgrimirse a favor de la lógica en el marco del razonamiento legal, gira en torno a establecer en la misma línea de Habermas (2003) que el derecho es una práctica comunicativa ${ }^{7}$. Lo anterior deriva en una afirmación adicional, constituida en que, dentro de la práctica jurídica, es necesario el entendimiento, en tanto, el derecho, como marco de desarrollo de la práctica jurídica, requiere al igual que en el mundo de la vida, condiciones básicas de inteligibilidad, condiciones que se cumplen mediante la argumentación. La argumentación a su vez, como estructura básica del entendimiento, se vale de dos aspectos esenciales, los cuales según Feteris (2007) son la lógica y la retórica, refiriéndose a ellos como enfoques de argumentación ${ }^{8}$.

\footnotetext{
${ }^{5}$ Punto el que ubica a Dworkin.

${ }^{6}$ Para García Amado: A lo que el positivismo está atado es a que, dicho simplificadamente, el Derecho solo es positivo. En otras palabras, que podremos ver principios (o directrices, etc.) entre las normas de un sistema jurídico-positivo, pero que lo que como Derecho no hay son normas suprapositivas o que sean jurídicas porque son morales y sin ser positivadas o reconocidas por normas puestas el sistema jurídico-positivo. Que el positivista no vea los principios moral-jurídicos de Dworkin, no obedece a un defecto accidental del positivismo, sino que va con su mismo concepto. Los positivistas pueden perfectamente ser tales si asumen que entre los enunciados normativos de un sistema jurídico hay reglas y principios (o directrices, o...) pero no si admiten que hay normas morales que por si son Derecho, que son jurídicas (además de morales) aunque vayan contra los contenidos de ese sistema jurídico-positivo (2015, p. 131).

${ }^{7}$ Viola y Zaccaria (2007) tienen una consideración similar, sobre una base conceptual idéntica, y consideran en esa misma línea de principio que uno de los fines del derecho es permitir la comunicación de los asociados y solucionar los problemas de coordinación social, empresa en la que el derecho intenta eliminar la incomunicabilidad y transformar el conflicto sin suprimirlo con el uso de la fuerza, por ello sostienen que el derecho es una práctica comunicativa.

${ }^{8}$ Esta afirmación la sustenta en el hecho de considerar que para Feteris (2007) el objetivo general de la teoría de la argumentación jurídica es establecer cómo se pueden analizar y evaluar adecuadamente los argumentos, de manera que al no existir normas particulares que determinen la metodología de
} 
De esa manera, cuando se tiene una razón que se pretende aducir como una forma de justificar una acción en el marco de la práctica judicial, se requiere explicitarla por medio de la argumentación, pero la argumentación solo cumplirá su objeto (adhesión y aceptabilidad) si cumple con dos presupuestos: (i) que tenga estructura lógica identificable y (ii) que puedan convencer al destinatario. De allí que Atienza sostenga que "la argumentación jurídica no se identifica con la lógica, pero la lógica es una dimensión esencial de la argumentación" (2013, p. 33), precisando que todos los argumentos tienen una determinada forma ${ }^{9}$, de la cual se ocupa la lógica y que ella consta de tres elementos: "las premisas, la conclusión y la relación que se establece entre esos elementos y la inferencia" (Atienza, 2013, p. 171).

Existen muchas formas de justificar el papel de la lógica al interior de la práctica jurídica (término generalizador que abarca tanto el ejercicio de los litigantes como de los jueces), pero para mí, la más relevante, se encuentra contenida en uno de los pilares fundamentales del proceso civil, laboral, y administrativo, que tiene desarrollo en el código general del proceso en el artículo 167, que a la letra reza:

Artículo 167. Carga de la prueba. Incumbe a las partes probar el supuesto de hecho de las normas que consagran el efecto jurídico que ellas persiguen.

La referida disposición desarrolla el concepto de norma planteado por Kelsen (Kelsen, 2013) estableciéndola como un juicio hipotético, en la medida que establece una relación entre una condición y una consecuencia jurídica, la cual, como lo señala Diez Picazo (2008), se caracteriza porque su esquema presenta, prima facie, dos partes distintas: la primera parte puede denominarse supuesto de hecho y la segunda parte recibe el nombre de consecuencia o efecto jurídico.

De esta manera la prosperidad de una pretensión, en un proceso, civil, laboral, y administrativo, o lo que es lo mismo, la aplicación de la consecuencia jurídica contenida en una norma dependerá de la demostración del supuesto de hecho identificado en ella, lo que puede explicarse de la siguiente manera:

1. si $p$, entonces debe ser $q$

2. $p$

3. debe ser $q$

evaluación, se debe recurrir a propuestas teóricas, en la medida que ellas buscan determinar normas ideales que propicien argumentos sólidos, y racionales, en tanto aceptables por quienes participan en la práctica legal, de suerte que para evaluar los méritos de la argumentación jurídica se presuponen de ciertas normas de racionalidad con base en las cuales se puede establecer si un argumento es sólido.

${ }^{9}$ Sostiene Atienza que se puede considerar como la forma de un argumento "aquello que queda del mismo cuando se hace abstracción del significado concreto de las proposiciones que lo componen y del contexto en el que se argumenta" (2013, p. 171). 
En este esquema debemos probar $p$, con el propósito de que se aplique la consecuencia jurídica $q$, o como lo señala De santo "la parte que afirma la existencia de un hecho al que atribuye alguna consecuencia jurídica, debe, ante todo, alegar la coincidencia de ese hecho con el supuesto fáctico de la norma o normas invocadas en su apoyo procesal" (2000, p. 85). Las dificultades que se generan, y de donde suscitan los conflictos que se surten y son tratados por vía judicial radican en establecer ¿cuál es la regla: si $p$, entonces debe ser $q$ ?, es decir, identificar la fuente de derecho aplicable al caso concreto, entendiéndose este como un problema de relevancia o validez ${ }^{10}$. Existirán, además, problemas de interpretación en los cuales deba identificarse el sentido de p; problemas de calificación y probatorios, donde se determine si $p$ se encuentra probado ${ }^{11}$.

La lógica juega un papel esencial en la solución de los problemas de interpretación y los problemas probatorios, sin dejar de lado que ayudan, aunque en menor medida en los de validez o relevancia, teniendo en cuenta que la solución de estos apela a cargas valorativas o morales, que merecen una justificación adicional.

La relevancia de la lógica en los problemas de interpretación, surge específicamente debido a que tal y como sostiene Comanducci (2009) ${ }^{12}$, la norma es un producto (para él interpretativo, de una formulación normativa) y por lo tanto podemos denotarla como una regla con significado ya atribuido. Esta idea es uno de los pilares de la noción de norma desarrollada por Kelsen $(2013)^{13}$, pues este la entiende como regla derivada o producto interpretativo. De allí MacCormick (2016) justifica la relación entre la lógica y la retórica, en específico en el momento en que la lógica sustenta la retórica, esto es, al identificar dentro de lo que Hart (1998) denomina textura abierta del lenguaje, los universales con los que debe llevarse a cabo la instanciación, sobre la que la retórica trabajará. Lo anterior tiene sentido en la medida que norma jurídica no se encuentra dentro del texto jurídico o disposición normativa, pues "si tal norma existiese es claro que antes de él la encontrarían las partes y no litigarían” (Satta, 2000, p. 335), es por ello que el juez debe crear la norma, y esto se realiza con la ayuda de la interpretación mediante un acto de concreción. Esa creación no puede entenderse al punto de la invención sin limitaciones, pues existen dentro del marco de la disposición a interpretar unos elementos o vías que suelen determinar más o menos el camino que debe el juez recorrer. Por ende, cuando existe la posibilidad de encontrar

\footnotetext{
${ }^{10}$ Sostiene MacCormick, (1978) citado por Atienza, (2005) que existen problemas de relevancia, "cuando se producen dudas sobre cuál sea la norma aplicable al caso, es decir "no cómo ha de interpretarse determinada sino si existe una tal norma $(p \rightarrow q)$ aplicable al caso" (p. 113).

${ }^{11}$ De manera amplia desarrollo cada uno de esos problemas en Guette Hernandez (2014).

${ }^{12}$ Comanducci señala que "Lo que se ha dicho hasta ahora tiene sentido si usamos norma como significado ya atribuido por el juez a una formulación normativa, o bien como formulación con su significado incorporado" (2009, p. 28).

${ }^{13}$ Punto en el que además concurren Guastini (2014), Alf Ross (2000), Taruffo entre muchos otros.
} 
diversos sentidos de la norma, lo que se hace es una elección entre aquella que corresponda en mejor medida con la realidad. De esta manera, mostraré cómo la lógica tiene un papel relevante en la construcción de las normas, específicamente en la identificación de los universales sobre los que la lógica trabajará. Realizaré, además, un breve recorrido en el papel que cumple la lógica dentro de la solución de los problemas probatorios.

\section{Punto de partida, la textura abierta del lenguaje utilizado en las reglas de derecho}

Prima facie podemos asumir que las reglas —si $p$, entonces debe ser $q$ - son creadas por el legislador, sin embargo y debido a que estos apelan a términos generales, en atención a que de esa forma puede abarcar un mayor número de posibilidades, se deriva que estas generalizaciones (en cuanto a personas y a clases de actos, cosas y circunstancias) deban dejar abierto un campo de posibilidades en torno a lo que se quiere comunicar y de allí a que existan dudas sobre lo que se quiso expresar, fenómeno que acontece, inclusive, aun cuando se quiso comunicar algo específico. A este fenómeno Hart (1998) lo denomina textura abierta del derecho y

\footnotetext{
Significa que hay, por cierto, áreas de conducta donde mucho debe dejarse para que sea desarrollado por los tribunales o por los funcionarios que procuran hallar un compromiso, a luz de las circunstancias, entre los intereses en conflicto, cuyo peso varía de caso a caso (1998, p. 168).
}

La explicación que lleva a cabo Hart (1998) sobre la textura abierta del derecho, parte o toma como punto de inicio la indeterminación del lenguaje, la cual es una necesidad del legislador al momento de comunicar las reglas, pautas o criterios de conducta, que constituyen el principal instrumento de control social. En efecto, señala Hart (1998), estas deben llevarse a cabo a partir de pautas generales y no particulares, en tanto solo de esa forma se podrán entender por multitudes. De allí que deba referirse a clases de personas y a clases de actos, cosas y circunstancias, pues solo ante la difusión de esas pautas, bajo esas características, se podrán regular actos o circunstancias particulares para todos. Para MacCormick (2016) la textura abierta es una consecuencia del lenguaje natural con el que se confeccionan las fuentes del derecho, todas las que permiten llevar a cabo formulaciones normativas completamente contradictorias sobre idéntica disposición. Esta característica de las reglas implica acrecentar el ámbito de indeterminación del derecho, en razón a que las lenguas naturales estén afectadas por la ambigüedad, la vaguedad y la textura abierta, implicando que al momento de determinar su sentido especifico, deba llevarse a cabo un acto volitivo, que puede ser interpretativo o argumentativo, ceñido al criterio individual de quien lleva a cabo esa función, y desembocar en conclusiones diversas y contradictorias, que emanen de la misma fuente. Este 
proceso de derivación es el que culmina con la identificación de las normas en sentido estricto, y por ende las reglas de contenido — si $p$, entonces debe ser $q$ -

Ahora bien, asumiendo lo establecido por Kelsen (2013) según lo cual: (i) en la estructura de las reglas existen universales, (ii) que las normas son un producto interpretativo, (iii) que la interpretación es el sentido de la norma por aplicar, cuyo propósito es la determinación del marco constituido por la norma, (iv) que la interpretación, la lógica y la argumentación sirven para completar los elementos que faltan en la norma; se genera que deban identificarse aquellos términos generales inmersos dentro del lenguaje de las reglas, para luego sí poder construir la norma que se va a aplicar, lo cual se lleva a cabo con un acto de instanciación.

\section{La instanciación}

Como se señaló, en la estructura de las reglas encontraremos universales, o conceptos, que se constituyen en categorías generales - el consumidor, la muerte, la lesión, la causa-, los cuales, gozan de una textura abierta del lenguaje. La consecuencia de esa vaguedad, es la imposibilidad de aplicación a un caso específico de determinada regla, requiriendo la necesidad de un acto volitivo que determine su sentido especifico, llevando a cabo un proceso de instanciación particular, a partir de un ejercicio interpretativo o argumentativo, procurando, en el marco de la ley, identificar su sentido normativo específico. De esa manera, por ejemplo, cuando una disposición incorpore dentro de sus hipótesis el concepto de consumidor, habrá que instanciarlo o determinar su sentido especifico, pues solo de esa manera podrá determinarse su sentido prescriptivo. Este acto orientado a determinar el sentido prescriptivo de una norma es denominado por MacCormick (2016) como instanciación.

Siendo así, señalaremos como disposiciones normativas aquellas reglas que contengan universales o conceptos que impidan su aplicación específica, por ser indeterminados. Denominaremos norma a aquella regla de derecho que establezca una relación entre hechos, y que esa relación que existe entre tales, sea el resultado de prescribir o autorizar determinada conducta y que, además, sea el producto de la instanciación realizada sobre los universales y conceptos contenidos en las disposiciones normativas. De esa manera, y en el mismo sentido que García Máynez (2002), sostendremos que la norma es una regla derivada de una disposición normativa, cuya característica esencial es la de eliminar de su contenido cualquier ambigüedad o indeterminación en el lenguaje empleado en la primera. Para Cisneros Farías la norma jurídica es además un juicio lógico, debido a que por su naturaleza conceptual debe comunicar un significado, sosteniendo además que "ha sido establecida para comunicar a los seres humanos por medio de un lenguaje común y técnico, significados prescriptivos para su adecuado comportamiento social" (2009, p. 49). 
Comoquiera que ese acto de instanciación se lleva a cabo en el marco de un proceso judicial, se genera que la norma se constituya, por su parte, en aquella regla individual creada por un juez o administrador de justicia, constituyéndose por ende, en obligación de un juez determinar su contenido, previo a su aplicación, circunstancia que impone a su vez, que deba primeramente identificar aquellos conceptos y universales que deben ser objeto de interpretación y luego asignarles un sentido según lo considere apropiado, desde el punto de vista político o moral. La instanciación es, en ese marco, el sentido de la norma por aplicar, el resultado de esta actividad no puede ser otro que la determinación del marco constituido por la norma y, por consiguiente, la comprobación de las diversas maneras de Ilenarlo.

\section{La función de la lógica en la instanciación}

Tal y como lo planteamos anteriormente, la lógica identifica conceptos y universales con los que procederá luego a trabajar la retórica y lo hará de manera que los procederá a instanciar, esto es, a identificar su contenido específico y luego a procurar su convencimiento o adhesión. Este trabajo es inicialmente interpretativo y después argumentativo. Vale decir, sin embargo, que cuando se argumenta, se presentan razones de manera desordenada y se hacen únicamente bajo la consideración de apoyar una determinada tesis. Otras veces se apela a argumentos que se llevan a cabo en una sola oración, otras más elaborados, pero con independencia de la extensión u organización, acontece que no respetan una estructura, lo que dificulta la identificación de las razones que apoyan una determinada tesis y la tesis que se apoya.

Esto es importante porque, una vez se identifican los conceptos y universales, deberán exteriorizarse las razones que justifican aplicar determinada interpretación. Esta actividad es eminentemente argumentativa, pero para poder tener una función de adhesión, debe al menos, o mínimamente, gozar de claridad. Un argumento es, así, un conjunto de razones que propenden por apoyar una determinada tesis, o como lo sostiene Weston "un conjunto de razones o de pruebas en apoyo de una conclusión" (2005, p. 11), pero para poder apoyarla, deben cumplir otro requisito adicional, cuál es su claridad. Así, entonces, la fuerza del argumento, tal y como se hizo ver, dependerá de dos elementos esenciales: su claridad, y la capacidad adhesión o de convencer. La claridad depende de su estructura, estructura que le proporciona la lógica. Así, de nada sirve tener una razón si es imposible explicitarla o darla a entender, entonces para cumplir con el objeto de convencer al destinatario de los argumentos, se requiere que estos sean claros, propósito que solo puede cumplirse apoyándose en un método que permita comunicar de manera entendible, papel que cumple perfectamente la lógica como herramienta que estructura el pensamiento. Por consiguiente, la claridad de un argumento dependerá de la estructura que se le aplique al mismo, 
siendo la lógica el método que mejor garantiza cumplir ese propósito; deviniendo por contera que la fuerza de un argumento dependa entonces: (i) de su estructura lógica identificable y (ii) que pueda convencer al destinatario.

Bonorino (2011) hace referencia a la estructura lógica de un argumento y plantea que estos son
un conjunto de enunciados en el cual un subconjunto de dichos enunciados constituye las razones para aceptar otro de los enunciados que lo componen. A los enunciados que constituyen las razones se les denomina premisas, y al enunciado que se pretende apoyar con estas se lo llama conclusión (2011, p. 21).

En ese sentido la conclusión será el argumento que se quiere defender, y las premisas, los argumentos que se utilizan para defender la tesis principal. Existirán, además, sub-argumentos que tendrán como conclusión a premisas que conforman el argumento central. Tengamos en cuenta, además, que para la construcción de argumentos podemos apoyarnos en diversas formas lógicas, y en específico para la construcción de normas, a las deductivas. Dentro de estas tenemos el modus ponens, o afirmando afirmo, su característica esencial es tener un enunciado condicional afirmativo como premisa mayor, la premisa menor se compone por una afirmación de la condición o hipótesis antecedente del enunciado condicional.

1) Si llueve me mojaré (si $p$ debe ser $q$ )

2) Llueve $(p)$

3) Entonces me mojaré $(q)$

Otra característica esencial de este modo, es que la conclusión necesariamente debe ser la afirmación de la segunda parte del enunciado. El modus tollens o negando niego, tiene una amplia similitud a la primera de las formas lógicas mostradas, su diferencia esencial es que el antecedente se niega, y por lo tanto la conclusión no resulta ser afirmativa sino negativa.

1) Si llueve me mojaré (si $p$ debe ser $q$ )

2) No llueve $(p)$

3) Entonces no me mojaré $(q)$

Estos dos modos son muy utilizados al momento de construir el argumento principal y pueden utilizarse para lograr una transitividad entre las premisas, permitiendo dotar de claridad los conceptos y universales contenidos en el antecedente, requiriendo para ello sustituir el consecuente por términos diversos 
que se conforman por su significado ${ }^{14}$, por lo general denotativo ${ }^{15}$, veamos:

1) El que matare a otro incurrirá en pena de prisión (si $p$ debe ser $q$ )

2) Matar significa quitar los signos vitales (si $p$ debe ser $h$ )

3) Pedro ha quitado los signos vitales de juan $(h)$

4) Por lo tanto pedro incurrirá en penal de prisión (Entonces q)

Como se aprecia, en este modo lógico, al igual que los primeros modos trabajados, la premisa mayor tiene una estructura condicional; la gran diferencia radica en que en la segunda premisa toma el antecedente $(p)$ de la primera y la remplaza por su significado $(h)$, la cual posteriormente constituirá el antecedente de la primera premisa.

El tercer modo lógico es el silogismo hipotético, cuya característica esencial es sustituir el consecuente de la primera premisa por su significado, o por otro término co-relacional, veamos:

1) Si usted estudia diversidad de culturas entenderá que existen otras costumbres (si $p$ debe ser $q$ )

2) Si usted comprende que existe una diversidad de costumbres humanas, entonces pone en duda sus propias costumbres (si $q$ debe ser $r$ )

3) Por lo tanto si usted estudia otras culturas pone en duda sus costumbres

(si $p$ debe ser $r$ )

La cuarta forma lógica que podemos emplear es el silogismo disyuntivo, "en ellos no afirmamos ninguno de los enunciados que lo componen, solo decimos que uno de los dos resulta verdadero" (Bonorino, 2011, p. 60). La forma de representar la disyunción es a partir de la partícula "o". Con esta forma no se busca afirmar una u otra opción presentadas en la disyunción, solo plantear que una de las dos es verdadera, tenido en cuenta el no suceso de la otra, veamos:

1) El color de la puerta es marrón o rojo $(P$ o $Q)$

2) La puerta no es roja (No Q)

3) Por lo tanto la puerta es marrón $(P)$

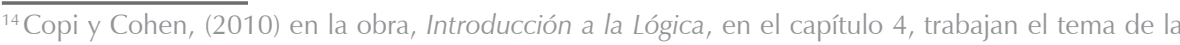
definición, desarrollando en dicho capitulo, las técnicas acá dispuestas. Para los autores, la definición estipulativa comprende asignar un significado determinado a un símbolo; la definición explicativa busca hacer más preciso un significado vago, siendo fieles al uso establecido; y la definición teórica intenta formular una descripción teórica o científicamente adecuada de los objetos a los que se refiere el término (p. 169ss.).

${ }^{15}$ Moreso y Villajosana: “La denotación o extensión de una palabra está compuesta por los objetos por ella nombrados, es decir, los objetos que constituyen la clase que nombra. La connotación o intención, constituye el conjunto de propiedades que un objeto debe tener para ser nombrado por la palabra" (2004, p. 151).
} 
La característica de este modo se constituye en que la premisa dos siempre es una negación de uno de los enunciados que conforman la primera premisa. Otra característica es que, a pesar de existir una negación, la conclusión es afirmativa.

Así entonces, en el contexto jurídico, nadie empieza a argumentar con una hoja en blanco, siempre se inicia con una proposición, que por lo general se constituye en la validez de una disposición normativa, la cual debe mostrarse coherente y consistente con el sistema; sistema integrado por fuentes formales del derecho (leyes, jurisprudencia, doctrina), luego, identificar los conceptos y universales, que al no ser ni autointerpretables ni autoaplicables, deberán instanciarse; actividad que se llevará a cabo mediante métodos de interpretación, que luego procederán a justificarse mediante $\operatorname{argumentos}^{16}$.

Asumiendo que la instanciación es el acto de determinar el sentido normativo, la lógica es para ella una herramienta de sistematización y control de variables. Partiendo de la noción de disposición normativa y su característica esencial de poseer universales y conceptos, generales y abstractos, se impone que la primera función que cumpla la lógica, es determinar el sentido de ellas, y controlar una coherencia de sus variables. En ese paso, logramos como resultado enunciados lingüísticos con sentido prescriptivo.

Así, entonces, teniendo en cuenta que las proposiciones con las que inicia una controversia jurídica son, por sobre todo, disposiciones normativas, y estas a su vez son enunciados lingüísticos, se genera que, para determinar el paso de lo más básico a lo más complejo debamos apoyarnos en la semántica, la sintaxis y la pragmática, como herramientas de la lógica proposicional ${ }^{17}$. En ese marco, tal y como lo establece Calvo García (2010), la definición es un instrumento adecuado para fijar el significado jurídico de ciertos términos técnicos y evitar así la confusión

\footnotetext{
${ }^{16}$ En este punto, y cuando se lleva a cabo un determinado litigio, se genera un escenario complejo, en el que se presentan argumentos, desligados de cualquier estructura, que no son entendibles por quien administra justicia, pero que no puede ser un óbice para no tomarlos en cuenta, dado el carácter tuitivo de la mayoría de los asuntos jurisdiccionales (ejemplo de ello los civiles, laborales, y administrativos, en los que debe interpretarse la demanda) y por ende se impone la necesidad de reconstruirlos. Este proceso de reconstrucción es, por, sobre todo, un acto de tamizar, en el entendido que se busca disminuir la complejidad. Desde esa perspectiva, el tamizaje le permite al juez reconstruir la argumentación y en ese paso identificar la norma derivada de la disposición, tomando en cuenta que, para la determinación de ella, deben tomarse en consideración las formulaciones efectuadas por las partes en el proceso, o plantear con base en esa discusión una propia. De esa manera, la lógica sustenta la retórica, en atención a que permite identificar los universales sobre los que debe llevarse a cabo la instanciación, tarea que se efectúa con la ayuda de la retórica.

${ }^{17}$ Para Barros Cantillo (1994) la Sintáctica hace referencia a las reglas que regulan las relaciones existentes entre símbolos de un lenguaje sin atender su significado, la semántica investiga las relaciones que se presentan entre las expresiones de un lenguaje y los objetos designados por tales expresiones. Su función es establecer la denotación o significado de un símbolo. De esa manera, señala el mismo autor que el paso definitivo de lo sintáctico a lo semántico tiene lugar cuando se sustituyen las variables "el que" o "mate" por su verdadero significado. La pragmática por su parte, son las relaciones existentes entre los símbolos de un lenguaje y quienes la usan (p. 14).
} 
de las palabras en el discurso ordinario, permitiendo entonces, garantizar la claridad requerida para dotar de fuerza el argumento. Las definiciones Pueden ser léxicas o informativas, estipulativas, redefinitorias o explicativas. La definición léxica "es descriptiva, nos dice aquello a lo que ciertas personas hacen referencia al usar una cierta palabra en un tiempo y en un lugar particulares" (Calvo García, 2010, p. 112). La definición estipulativa, "consiste en fijar explícitamente la relación entre alguna palabra y algún objeto, acuñando un término nuevo o dotando a un término ya en uso de un significado nuevo" (Calvo García, 2010, p. 112). La redefinición "es un tipo particular de definición estipulativa cuyo cometido es precisar el significado de un término existente" (Calvo García, 2010, p. 112).

La interpretación, y la argumentación desembocaran en una norma, precisando que esta, más allá que una regla derivada, es una regla con una estructura definida, esto es un supuesto de hecho y una consecuencia jurídica. Pero en una norma no solo existe un supuesto de hecho o un supuesto o hipótesis o condición, que se constituye en una previsión o una anticipación hipotética respecto de una posible o incluso probable realidad futura, que puede ser un concepto que hace referencia a un hecho determinado; y una consecuencia jurídica que se constituyen en los que deberán tener lugar en el caso de haberse realizado el supuesto normativo; pues además, como toda construcción lingüística debe identificar el sujeto o destinatarios de ella, y el predicado, o atributos del sujeto.

El sujeto puede ser universal o general, que acontece cuando la norma se dirija a una clase más o menos amplia de agentes indeterminados en previsión de que todos o algunos miembros de la comunidad jurídica pueden verse involucrados en determinado tipo de acciones o situaciones (Calvo García, 2010, p. 105) (los colombianos, los hijos), otras veces se trata de un sujeto particular, en este supuesto, el sujeto pasivo, la persona o las personas a las que se dirige la norma, está específicamente determinado pudiendo ser incluso un sujeto individual (Calvo García, 2010, p. 105). Este sujeto particular puede apelar a un amplio y variado conjunto de sujetos que se connotan dentro del término clase, pero que pueden determinarse de manera específica por las cualidades que comparten, (por ejemplo, el presidente, los congresistas). "El supuesto normativo es la hipótesis de cuya realización depende el nacimiento del deber estatuido por la norma" (García Máynez, 2002, p. 13) consiste en una previsión o anticipación hipotética de una realidad futura formulada por medio del lenguaje (Calvo García, 2010, p. 97). En la hipótesis se establecen las condiciones de hecho (hechos, actos, o estados jurídicos) que habrán de realizarse para que se produzcan las consecuencias contenidas en la disposición normativa (Monroy Cabra, 2010, p. 323), y se constituyen en las condiciones para que se realice la consecuencia jurídica. Pueden ser simples, cuando constan de una sola hipótesis, y complejos, cuando contemplan más de una hipótesis para la aplicación de la consecuencia jurídica. Los supuestos complejos pueden ser independientes cuando a pesar de establecerse diversas hipótesis, la aplicación de la consecuencia jurídica, no 
depende de la realización de todas; y dependientes, en aquellos eventos en los que se requiere la conjunción de todas las hipótesis para la aplicación de la consecuencia jurídica. Pueden ser combinados, o autónomos, los combinados son aquellos que se forman producto de la conjunción de varias disposiciones normativas, y autónomos son aquellos que se extraen de una sola disposición normativa. La consecuencia jurídica consiste en una previsión de derechos y obligaciones de carácter general.

\section{Importancia de la lógica y la instanciación universal en la práctica}

Son muchos los escenarios, tanto en aulas de clases con estudiantes de pregrado, como en espacios donde se congregan abogados, en los que indago entre los asistentes, ¿dónde debe iniciar la construcción de una demanda? La respuesta más común se orienta a establecer: por el juez a quien se dirige, otros dirán por los hechos, otro grupo, por las pretensiones.

Su respuesta va orientada, sobre todo, por el conocimiento que tiene de la estructura establecida en los estatutos procesales para este acto, sin embargo, es preciso aclarar, como lo hago cuando formulo el cuestionamiento, que mi pregunta no va orientada a identificar cómo inicia una demanda, sino dónde inicia su construcción. Son dos fases diferentes, pues el producto terminado no debe coincidir necesariamente con la construcción. Así, por ejemplo, cuando vemos a un pintor, podemos detallar que su primera capa constituye el fondo de la pintura terminada, tal vez un árbol, una montaña o un riachuelo que se verán muy al fondo, y al final, podríamos pensar que se inició por lo primero que se observa, o lo que se encuentra adelante en la pintura.

De la misma manera sucede con la construcción de la demanda, en tanto, el hecho que inicio identificando el juez a quien se dirige, no significa que su construcción inicia por ese aspecto. Pero tampoco inicia con las pretensiones o los hechos, debido a que estos solo adquieren fuerza justificatoria, en la medida que se identifique el fundamento de derecho que los apoya. De esa manera, toda forma procesal (demanda, contestación, escrito de acusación, alegatos de conclusión, sentencia), debe iniciar por la identificación de la norma. Así, entonces, y al ser la norma una construcción normativa derivada de la identificación, y luego instanciación de una disposición, debemos sostener que la construcción de las formas procesales debe partir de allí, todo lo cual podemos encontrar ubicado en lo que normalmente se intitula: fundamentos de derecho.

La justificación de lo anterior, tal y como se hizo ver, se encuentra estatuida en el artículo 167 del CGP que tal, y como se mostró, impone que solo se aplique el efecto jurídico contenido en la norma, si probamos su supuesto de hecho. De esa 
manera, y a efectos de lograr la prosperidad de cualquier pretensión, debemos inicialmente identificar el supuesto de hecho de la norma, junto con su efecto o consecuencia jurídica; una vez determinados estos aspectos estableceremos como hechos de la demanda los supuestos de hechos, y las consecuencias como pretensiones, las pruebas deberán orientarse a demostrar los supuestos de hecho para lograr que se declaren prósperas las pretensiones. Veamos cómo funciona en la práctica. El artículo 21 del decreto 758 de 1990 será el elegido para poder explicar lo expresado, este a la letra establece:

» Artículo 21. Incrementos de las pensiones de invalidez por riesgo común y vejez. Las pensiones mensuales de invalidez y de vejez se incrementarán así:

» a) En un siete por ciento (7\%) sobre la pensión mínima legal, por cada uno de los hijos o hijas menores de 16 años o de dieciocho (18) años si son estudiantes o por cada uno de los hijos inválidos no pensionados de cualquier edad, siempre que dependan económicamente del beneficiario y,

» b) En un catorce por ciento (14\%) sobre la pensión mínima legal, por el cónyuge o compañero o compañera del beneficiario que dependa económicamente de este y no disfrute de una pensión.

Como podemos apreciar, el mismo tiene dos literales, a partir de los cuales pueden realizarse diversas construcciones normativas. Utilizaremos el segundo. La lectura de este literal expresa, que las pensiones mensuales de invalidez y de vejez se incrementarán en un catorce por ciento (14\%) sobre la pensión mínima legal, por el cónyuge o compañero o compañera del beneficiario que dependa económicamente de este y no disfrute de una pensión.

Los términos que deberían ser objeto de instanciación serían: (i) pensión de vejez e invalidez; (ii) pensión mínima; (iii) cónyuge; (iv) compañero permanente; (v) dependencia económica. Podemos plantear en aras de simplificar el ejercicio que, en el estado actual de los conocimientos jurídicos, es razonable señalar que existe un consenso sobre el significado de los términos (i) al (iv). Se generaría una complejidad diferente respecto del (v).

Si utilizamos un criterio interpretativo literal para instanciarlo o, lo que es lo mismo, una definición lexicográfica ${ }^{18}$, apoyados en el Diccionario de la Real Academia de la Lengua, concluiríamos que la dependencia económica es una subordinación a otro, servirle de complemento o ser regido por él. A todas luces, esta definición no proporciona un resultado satisfactorio, por lo que debe acudirse a una de tipo diferente a la literal a las que Guastini (2011) se refiere como

\footnotetext{
${ }^{18}$ Para Marmor la noción de interpretación es problemática, en tanto tiene diferentes acepciones, sin embargo, para él, interpretar y definir son términos concurrentes al punto de sostener que "interpretar es atribuir un significado a un objeto" (2000, p. 28).
} 
correctoras $^{19}$. Para eso utilizaremos un argumento de autoridad proporcionado por la Corte Constitucional, quien al interpretar la misma disposición señaló que:

A este respecto, la independencia económica se refiere "a tener la autonomía necesaria para sufragar los costos de la propia vida, sea a través de la capacidad laboral o de un patrimonio propio", o a la posibilidad de que "dispone un individuo para generarse un ingreso económico o disponer de una fuente de recursos que le permitan asumir las necesidades básicas, y garantizarse una vida en condiciones dignas y justas" (Sentencia C-066/16).

\section{Continúo señalando que}

para poder acreditar la dependencia económica, no es necesario demostrar la carencia total y absoluta de recursos - propio de una persona que se encuentra en estado de desprotección, abandono, miseria o indigenciasino que, por el contrario, basta la comprobación de la imposibilidad de mantener el mínimo existencial que les permita a los beneficiarios obtener los ingresos indispensables para subsistir de manera digna (Corte Constitucional, Sentencia C-066/16).

De esa manera asumiremos que la dependencia económica es aquella condición en que se encuentra un sujeto cuando requiere de otro para poder subsistir de manera digna. Así, y una vez instanciada la disposición tendríamos la siguiente norma:

1. Un pensionado tendrá derecho al incremento del 14\% sobre su pensión mínima legal, en los eventos que se encuentre casado, y su cónyuge dependa económicamente, de este y no disfrute ninguna pensión (si $p$ entonces debe ser $q$ ).

Plantearemos como sub-argumento, al instanciar dependencia económica el siguiente:

2. Un criterio de interpretación literal no es satisfactorio para definir o interpretar el concepto de dependencia económica.

3. Al no ser satisfactorio el criterio de interpretación literal para definir o interpretar el concepto de dependencia económica se utiliza uno corrector.

4. El argumento corrector utilizado, se funda en un argumento de autoridad aportado por la Corte Constitucional al interpretar la noción de dependencia económica.

\footnotetext{
${ }^{19}$ Para Guastini la interpretación correctora por su parte se presenta como una desviación al significado propio de las palabras, y eventualmente como corrección de la voluntad legislativa, en ese sentido será correctora toda aquella interpretación que se aparta del significado literal del texto y le adscribe un significado distinto (2011, p. 26).
} 
5. Para la Corte Constitucional la dependencia económica es aquella condición en que se encuentra un sujeto cuando requiere de otro para poder subsistir de manera digna.

6. Por lo tanto, la dependencia económica es aquella condición en que se encuentra un sujeto cuando requiere del aporte económico otro para poder subsistir de manera digna.

La norma en consecuencia sería la siguiente:

7. Un pensionado tendrá derecho al incremento del 14\% sobre su pensión mínima legal, en los eventos que se encuentre casado, su cónyuge requiere del aporte económico de su esposo para poder subsistir de manera digna, y no disfrute ninguna pensión (si $p$ entonces debe ser $q$ ).

Teniendo en cuenta la norma identificada plantearemos lo siguiente:

1. El sujeto de la norma es particular o calificado.

2. La hipótesis es compleja dependiente, debido a que existan varias y deben darse todas.

3. Las hipótesis son: a) que sea pensionado; b) que se encuentre casado; c) que el cónyuge requiere del aporte económico de su esposo para poder subsistir de manera digna; d) que el cónyuge no se encuentre pensionado.

4. La consecuencia jurídica se constituye en el incremento de la pensión mínima en un $14 \%$.

Todos razonamientos explicitados deberán constar en los fundamentos de derecho de la demanda. Una vez asentados se procede con la confección de los hechos.

Los hechos que debe contener esta demanda serán los siguientes:

1. Pedro está pensionado.

2. Pedro está casado.

3. La cónyuge de Pedro se llama María.

4. María requiera del aporte económico de su esposo para poder subsistir de manera digna.

5. María no recibe ningún tipo de pensión. 
Las pretensiones de la presente demanda serán:

1. Que se declare que Pedro está pensionado.

2. Que se declare que Pedro está casado.

3. Que se declare que María es la esposa de Pedro.

4. Que se declare requiere del aporte económico de Pedro para poder subsistir de manera digna.

5. Que se declare que María no recibe ningún tipo de pensión.

6. Que se declare que Pedro tiene derecho al incremento pensional del 14\% sobre su pensión mínima.

7. Que se condene a Colpensiones a pagar a favor de Pedro la suma de xxx millones de pesos por concepto de retroactivo pensional.

Como se aprecia, cada hecho debe tener una pretensión declarativa ${ }^{20}$, en atención a que la aplicación de la consecuencia jurídica solo es posible si se declara la existencia de los supuestos de hecho de la norma. Además de las pretensiones declarativas incorporadas ( 1 a la 5 ) existe una constitutiva ${ }^{21}$ que va de la mano o tiene una relación intrínseca con la consecuencia jurídica; y se debe imponer en la mayoría de los eventos una de pretensión de condena ${ }^{22}$ cuyo carácter es resarcitorio o indemnizatorio.

Luego de identificados los supuestos de hechos de la norma, y el efecto jurídico que ella persigue, deben probarse los primeros para que se aplique lo segundo. En ese sentido deberá en la siguiente fase esta determinar los medios de pruebas en que se sustentará la demanda. Estos tienen una relación directa con los hechos de la misma, de manera que el medio de prueba 1, debe acreditar el supuesto de hecho o hipótesis 1, el medio de prueba 2, el hecho 2, y así sucesivamente. Veamos:

1. Resolución de reconocimiento de la pensión.

2. Registro civil de matrimonio.

3. Declaración de Mariano y Juan.

4. Es una negación indefinida.

El siguiente cuadro puede explicar de manera más sencilla la relación existente:

\footnotetext{
${ }^{20}$ Para Rojas "en la pretensión declarativa el juez debe verificar si realmente ocurrieron los hechos cuyo reconocimiento judicial es solicitado" (2013, p. 205).

${ }^{21}$ La pretensión constitutiva tiene como objeto la alteración de la realidad, producto o debido a la creación, modificación o extinción una determinada relación jurídico-sustancial.

${ }^{22}$ Para Rojas "la pretensión de condena impone la indagación sobre los hechos que acarrean la prestación que ha de ser impuesta. Si aquellos no llegan a establecerse, esta no podrá imponerse" (2013, p. 206).
} 
Figura 1. Modelo demanda basada en razones legales

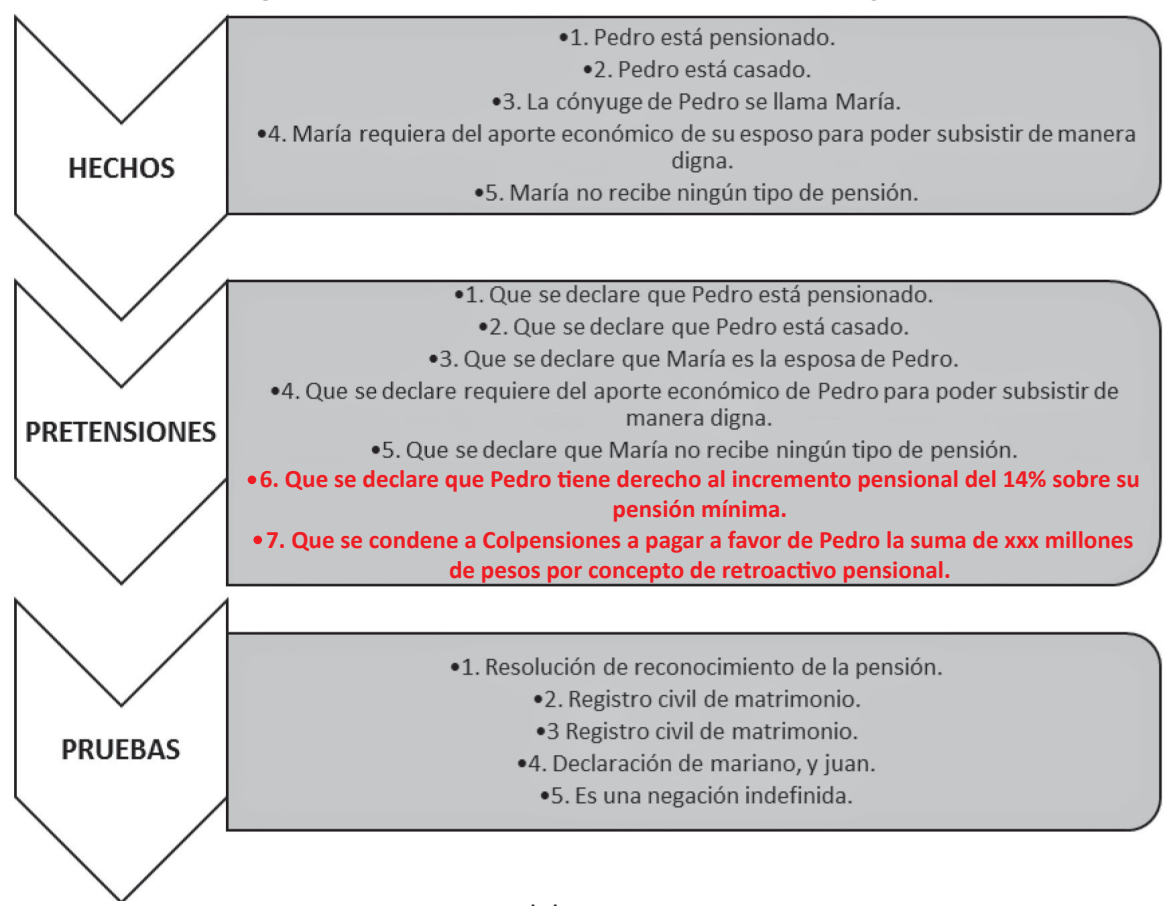

Fuente: elaboración propia

Lo previamente expuesto tiene como propósito que el manejo de la lógica ayuda a facilitar el entendimiento dentro de las formas procesales. Si bien en el presente solo se hizo referencia a la demanda, la misma utilidad tiene para la contestación de la misma, el escrito de acusación, y aún más para la sentencia. Sucede sin embargo que por lo extenso que merece esa explicación debe plantearse otro trabajo aparte.

\section{Importancia de la lógica en la cuestión fáctica}

Es un tema bastante extenso, que es imposible de agotar en 10 o 20 hojas, o en una ponencia de 45 minutos, sin embargo, realizaré una breve introducción, para mostrar como incide ella en el razonamiento judicial. Primeramente partiremos de la máxima según la cual, la apreciación probatoria se realiza mediante las reglas de la lógica ${ }^{23}$ y la sana crítica. Siendo así, y comoquiera que tanto la demanda como la contestación son proposiciones que se realizan al juez, es indispensable entender cómo funciona el razonamiento lógico para poder estructurar la actividad probatoria que se llevará a cabo.

${ }^{23}$ Para Devis Echandía sin lógica no puede existir valoración de la prueba, y esta se encuentra al lado de la razón y se utilizan para la valoración de la prueba (2012, p. 94ss.). 
Para esto lo primero que debe tenerse en cuenta, es que no existe una lógica única o univoca para el razonamiento probatorio. Lo segundo es que el razonamiento probatorio se lleva a cabo en fases y la tercera que las reglas probatorias son de diversa estirpe. En efecto, Ferrer Beltrán (2005) establece tres sub-conjuntos de reglas probatorias (2005, pp. 42ss.): el primer subconjunto está compuesto por reglas que versan sobre la actividad probatoria. Dentro de este subconjunto se incluyen reglas que establecen el inicio y/o el final de la fase de prueba, las formas para la práctica de la prueba, y la iniciativa o la carga probatoria. En el segundo subconjunto se encuentran las reglas que regulan los medios de prueba. Dentro de estas existen unas que determinan qué medios son admisibles para demostrar determinado hecho, otras solo los definen, y otras establecen obligaciones de decretar y practicar determinados medios de pruebas en casos específicos (prueba de ADN o inspección judicial). El tercer sub-conjunto versa sobre el resultado probatorio, dentro de este sub-conjunto encontramos las reglas que determinan la valoración de la prueba y se subdividen entre los dos sistemas más importantes: el de libre valoración de la prueba, y el de prueba legal. Dentro de este sub-conjunto se ubican las reglas de la sana crítica y valoración racional y las pruebas que establecen algún tipo de tarifa legal.

Teniendo en cuenta lo anterior, debemos tener presente que en materia probatoria al sostener que $p$ está probado, estoy afirmando a su vez, que los elementos A, B y C lo corroboran, que esos enunciados son medios de prueba, y que fueron aportados, controvertidos y valorados en las oportunidades probatorias establecidas dentro de determinada vía procesal. De allí se sigue que los enunciados probatorios sean enunciados correlacionales, en tanto y en cuanto solo y en la medida que exista un soporte probatorio, podrá afirmarse que determinado hecho se encuentra acreditado.

Ahora bien, no basta únicamente con soportar un enunciado probatorio con determinado medio de prueba, pues este debe tener un valor epistemológico y proporcionar un apoyo empírico al hecho que busca apoyar. Surge aquí la problemática en torno a la determinación de esos aspectos o la eficacia de los mismos. Aquí es donde tiene una participación importante la lógica y la sana crítica, pues tal y como sostiene Couture "las reglas de la sana crítica consisten en su sentido formal en una operación lógica" (2000, p. 19).

En materia lógica, debe precisarse que el razonamiento que surge en esta fase se lleva a cabo a partir de un encadenamiento de argumentos o inferencias parciales, que parten de las pruebas obtenidas o debidamente incorporadas al proceso, dentro de ellas podemos encontrar muy reducidamente las deductivas, además las inductivas y las abductivas. Para explicar de manera sencilla la concatenación de estas inferencias, resulta apropiado echar de mano del modelo argumentativo de Toulmin (2003), tal y como lo hace González Lagier (2011). 
Se asume en este modelo, como datos, los medios de prueba que soportan determinado enunciado probatorio; la pretensión será el enunciado probatorio o hipótesis que se soporta por los datos; la garantía es el elemento cardinal de este entramado, puede estar conformada por reglas de la experiencia, presunciones, o reglas probatorias; el respaldo será aquella regla de autoridad, contenida en la ley, la doctrina o la jurisprudencia que soporta la garantía. El siguiente ejemplo muestra cómo se desarrolla dentro del marco del razonamiento probatorio cada uno de los elementos del modelo de Toulmin (2003):

Figura 2. Modelo de Toulmin aplicado al razonamiento probatorio
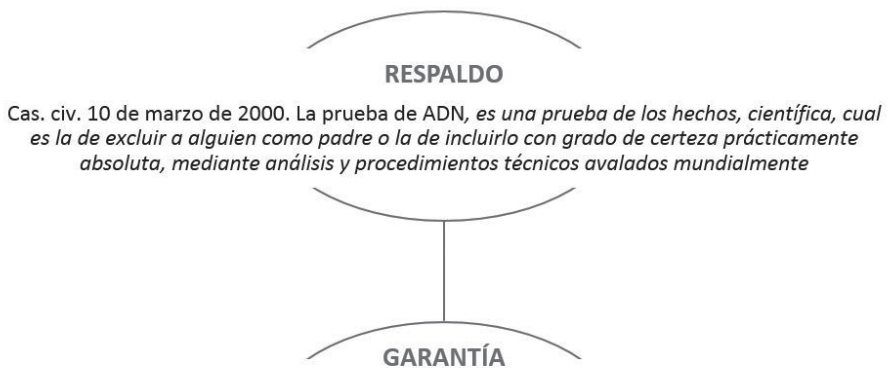

Artículo 1, Lev 721 de 2001. El artículo 7o. de la Ley 75 de 1968, quedará así:

Artículo 7o. En todos los procesos para establecer paternidad o maternidad, el juez, de oficio, ordenará la práctica de los exámenes que científicamente determinen índice de probabilidad superior al $99.9 \%$.

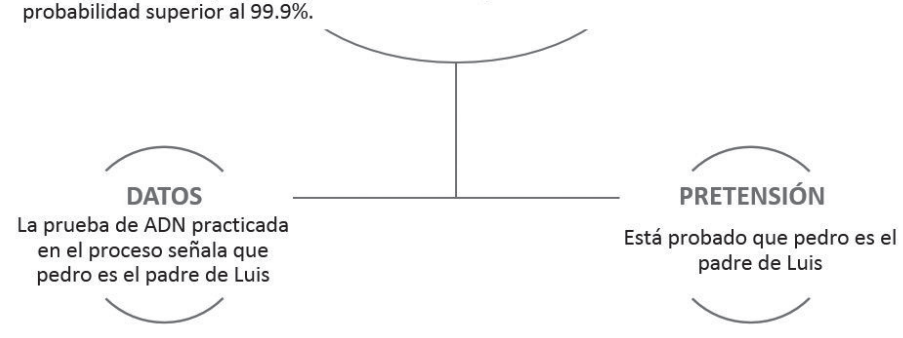

Fuente: elaboración propia

En este escenario, se plantea en la mayoría de las ocasiones garantías que son reglas de la experiencia, y escasamente garantías legales, como en el presente evento, esta, además, se constituye en aquella regla que permite el paso inferencial, y quien da un carácter o apoyo justificatorio a los datos frente a la pretensión, hechos probatorios o hipótesis que se pretende justificar.

\section{Conclusión}

Quiero concluir con un mensaje dirigido a los abogados litigantes, a jueces y fiscales, y especialmente a mis estudiantes de lógica jurídica: no podemos correr, si no aprendemos a caminar de manera adecuada. La anterior frase quiero emplearla como una analogía para sostener que, si no entendemos la estructura de 
un argumento, mucho menos podremos lograr adherir al destinatario del mismo, en tanto lo primero es elemento necesario y primordial para lograr lo segundo. Por ello, debe comprenderse que la lógica sí es relevante en el razonamiento legal, y que inclusive es la base de la argumentación para cuestiones práctico generales, como para formas procesales básicas, pero a la vez tan relevantes dentro de la práctica judicial como lo son: la demanda, la contestación, e inclusive el escrito de acusación.

Parece, como lo sostiene Atienza (2013), que comprender la dimensión esencial de la lógica en el razonamiento es una obviedad, obviedad que como el mismo autor lo sostiene, ha quedado enturbiada, y ello en razón al parecer de muchos de los que hacen parte de la práctica judicial de omitirla en la redacción de sus formas procesales, lo que redunda grandemente en la confección de demandas, y escritos de acusación farragosos que no se compadezcan ni identifiquen la relevancia del hecho contenido en la disposición que se emplea solicitar la aplicación de las consecuencias jurídicas que se persiguen. El tema ha tomado tal relevancia (la falta de forma de los actos procesales) que por ejemplo en materia penal, la Sala de Casación Penal de Corte Suprema de Justicia entre otras en sentencia del dieciséis (16) de abril de dos mil quince (2015), radicado $N^{\circ} 44866$, ha tenido que implementar una tesis sobre la necesidad de que el juez realice un control formal al escrito de acusación, muy a pesar que la Ley 906 de 2004, no establezca ese condicionamiento, y lo ha hecho por la falta de inteligibilidad de los actos introductorios (escrito de acusación) que desembocan "en afectación profunda de garantías o del proceso mismo". Claro que esta realidad es gravísima, debido a las repercusiones que generan en las garantías fundamentales, y especialmente la libertad de los destinatarios del ejercicio de la acción penal, pero es además penoso ver cómo un acto donde se involucran temas de trascendencia política y social debe ser devuelto a los miembros del ente acusador, por no respetar la forma argumentativa propia del acto procesal, al punto de no poder siquiera entender la relevancia del relato y su relación con las pruebas.

Otra razón que desemboca en la pérdida de importancia en el razonamiento legal, es aquella concepción que considera que la lógica debe trabajarse al margen del razonamiento, ya práctico general o legal. No debe perderse de vista, y en eso debo hacer mucho énfasis, que la importancia real de la lógica radica en su necesidad al momento de construir argumentos, desde práctico generales como los contenidos en el ensayo, hasta jurídicos como los contenidos en formas procesales como la demanda y su contestación. Empero, no puede trabajarse la lógica sin tomar en cuenta este norte, pues ello desemboca en una desidia desafortunada respecto de quienes deben aprenderse de memoria las 19 combinaciones válidas para la construcción de silogismos. No quiero demeritar con esto a los filósofos o matemáticos que imparten cátedras de lógica en los claustros universitarios, considero que, desde la práctica judicial, un programa 
más afortunado tendrá en cuenta y hará un gran énfasis en las estructuras básicas de los argumentos, en las reglas de inferencia, en la utilización de analogías, y en la construcción de formas procesales.

\section{Referencias}

Alexy, R. (2007). Teoría de la argumentación jurídica. Madrid: Centro de Estudios Políticos y Constitucionales.

Alexy, R. (2012). Teoría de los derechos fundamentales. Madrid: Centro de Estudios Políticos y Constitucionales.

Atienza, M. (2005). Las razones del derecho. Ciudad de México: Universidad Nacional Autónoma de México.

Atienza, M. (2013). Curso de argumentación jurídica. Madrid: Trotta.

Barros Cantillo, N. (1994). La lógica del silogismo jurídico. Bogotá: Librería Ediciones del Profesional.

Bonorino, P. y Peña Ayazo, J. (2006). Filosofía del derecho. Bogotá: Consejo Superior de la Judicatura.

Bonorino, P. (2011). Argumentación en procesos judiciales. Bogotá: Consejo Superior de la Judicatura.

Calvo García, M. (2010). Teoría del derecho. Madrid: Tecnos.

Cisneros Farías, G. (2009). Lógica jurídica. Ciudad de México: Porrúa.

Comanducci, P. (2009). Algunos problemas conceptuales relativos a la aplicación del derecho. En Positivismo jurídico y neoconstitucionalismo (pp. 11-40). Madrid: Fundación Coloquio Jurídico Europeo.

Copi, I. y Cohen, C. (2010). Introducción a la lógica. Ciudad de México: Limusa.

Couture, E. (2000). Pruebas y su valoración. En Valoración judicial de las pruebas (pp. 9-22). Bogotá: Editora Jurídica de Colombia.

De santo, V. (2000). La prueba en general. En Valoración judicial de las pruebas (pp. 82-103). Bogotá: Editora Jurídica de Colombia. 
Devis Echandía, H. (2012). Compendio de derecho procesal. Pruebas judiciales. Tomo II. Bogotá: Editorial Temis.

Diez Picazo, L. (2008). Experiencias jurídicas y teoría del derecho. Barcelona: Ariel.

Dworkin, R. (2005). El imperio de la Justicia. Barcelona: Gedisa.

Dworkin, R. (2014). Los derechos en serio. Barcelona: Ariel.

Ferrajoli, L. (2006). Garantismo. Madrid: Trotta.

Ferrer Beltrán, J. (2005). Prueba y verdad en el derecho. Madrid: Marcial Ponds.

Feteris, E. (2007). Fundamentación de la argumentación jurídica. Bogotá: Universidad Externado de Colombia.

García Amado, J. A. (2015). Pidiendo el principio. Dworkin y la teoría del derecho en serio. En El legado de Dworkin a la filosofía del derecho (pp. 127-157). Madrid: Centro de Estudios Políticos y Constitucionales.

García Máynez, E. (2002). Introducción al estudio del derecho. Ciudad de México: Porrúa.

González Lagier, D. (2011). Argumentación y prueba judicial. En Estudios sobre la prueba (pp. 103-148). Ciudad de México: Fontamara.

Guastini, R. (2011). Estudios Sobre La Interpretación Jurídica. Ciudad de México: Porrúa.

Guastini, R. (2014). Interpretar y argumentar. Madrid: Centro de Estudios Políticos y Constitucionales.

Güette Hernández, D. M. (2014). El modelo de argumentación consecuencialista. Derecho a Pensar, (1)1, 1-15.

Habermas, J. (2003). Teoría de la acción comunicativa. Bogotá: Taurus.

Hart, H. (1998). El concepto del derecho. Buenos Aires: Abeledo-Perrot.

Kelsen, H. (2013). Teoría pura del derecho. Bogotá: Géminis.

MacCormick, N. (2016). Retórica y Estado de Derecho. Lima: Palestra.

Marmor, A. (2000). Interpretación y teoría del derecho. Barcelona: Gedisa. 
Monroy Cabra, M. G. (2010). Introducción al derecho. Bogotá: Temis.

Moreso, J. J. y Villajosana, J. (2004). Introducción a la Teoría del Derecho. Madrid: Marcial Ponds.

Rojas, M. E. (2013). Lecciones de derecho procesal. Tomo I. Bogotá: Esaju.

Ross, A. (2000). Lógica de las normas. Granada: Comares.

Satta, S. (2000). Los poderes del juez. En Valoración judicial de las pruebas (pp. 333-363). Bogotá: Editora Jurídica de Colombia.

Taruffo, M. (2011). La prueba de los hechos. Madrid: Trotta.

Toulmin, S. (2003). Los usos de los argumentos. Barcelona: Ediciones Península.

Viehweg, T. (2007). Tópica y jurisprudencia. Pamplona: Arazandi.

Viola, F. y Zaccaria, G. (2007). Derecho e interpretación. Elementos de teoría hermenéutica del derecho. Madrid: Dykinson.

Weston, A. (2005). Las claves de la argumentación. Barcelona: Ariel. 